\title{
VULNERABILIDADES NO ENVOLVIMENTO FEMININO COM DROGAS: UM ESTUDO COM MULHERES EM SITUAÇÃO DE PRISÃO
}

\section{VULNERABILITY OF FEMALE DRUGS USERS: A STUDY WITH WOMEN IN PRISON SITUATION}

\author{
Geisa Copello Thomaz*, Jeane Freitas de Oliveira**, Tânia Christiane Ferreira Bispo*** \\ Autora para correspondência: Geisa Copello Thomaz - geisacop@hotmail.com \\ *Psicóloga, Especialista em Atenção Integral ao consumo e aos consumidores de substâncias psicoativas. Especialista em \\ Psicologia Jurídica e em Psicoterapia Clínica. Psicóloga do Conjunto Penal Feminino de Salvador, Bahia. \\ **Enfermeira, Doutora em Saúde Pública pela UFBA, Mestre em Enfermagem pela UFBA, Especialista em Enfermagem \\ Comunitária pela UFBA. Professora da UFBA. Salvador, Bahia, Brasil. \\ ***Enfermeira, Doutora e Pós-doutora em Saúde Coletiva pelo Instituto de Saúde Coletiva da UFBA- ISC/UFBA. Professora \\ Adjunta da Escola Bahiana de Medicina e Saúde Pública. Coordenadora do NUPEIS: Núcleo de Pesquisa Interfaces em \\ Saúde da Escola Bahiana de Medicina e Saúde Pública, Bahia, Brasil.
}

\section{R E S U M O}

\begin{abstract}
Introduçãa: $O$ envolvimento feminino com as drogas se dá de diferentes maneiras. A maioria das mulheres ainda ocupam posição coadjuvante neste tipo de crime, mas seja qual for a forma de participação, constitui um elemento de vulnerabilidade para essas mulheres. Objetivo: $O$ presente artigo teve como objetivo descrever elementos de vulnerabilidade no envolvimento feminino com drogas. Metodologia: Tratou-se de uma pesquisa qualitativa, desenvolvida com onze mulheres de uma penitenciária feminina de Salvador, BA, que cumpriam sentença por infrações relacionadas ao fenômeno das drogas. Para coleta de dados utilizou-se as técnicas de desenho estória-tema e a entrevista semiestruturada, cujo conteúdo foi analisado pela análise de conteúdo temática, norteada pelos princípios da Teoria das Representações Sociais. Resultados: Para as entrevistadas a influência de companheiro e amigos, traumas/revoltas da vida, dificuldades financeiras e a busca de visibilidade e poder foram apontados como elementos de vulnerabilidade para seu envolvimento com as drogas. Conclusão: Os resultados apresentados pelas mulheres em situação de prisão participantes refletem a condição da mulher num contexto de desigualdades e na busca de visibilidade, cujo consumo de drogas e a participação no narcotráfico se apresentam como estratégias de enfrentamento. Essas estratégias, contudo, ocasionam, dentre outros aspectos, situações de sofrimento para as próprias mulheres e seus familiares.
\end{abstract}

Palavras-chave: Mulheres; Drogas; Tráfico de Drogas; Vulnerabilidade. 
Introduction: The female engagement with drugs occurs of many ways. Most women still occupy an adjunct position in this type of crime, but whatever the form of participation, is an element of vulnerability for these women. Objective: The present article aims to describe vulnerability elements in the involvement of women with drugs. Methodology: This was a qualitative research, developed with eleven women from a women's prison in Salvador-BA, who have been serving sentences related to the drugs phenomenon. The story-theme drawings, as well as the semi structured interview techniques were used in order to collect data, whose content was analyzed through thematic content analysis, as guided by the principles of the Social Representations Theory. Results: To the women interviewed, the influence of a partner and friends, financial difficulties and the search for visibility and power were indicated as vulnerability elements related to their involvement with drugs. Conclusion: the results found by women in prison situation reflect the woman's condition in a context of inequalities and search for visibility, in which drugs consumption and participation in drug dealing are presented as strategies of confrontation. These strategies, nevertheless, cause, among other aspects, suffering to the women themselves and to their families.

Keywords: Women; Drugs; Drug Dealing; Vulnerability. 


\section{INTRODUÇÃO}

Os problemas relacionados ao consumo de álcool e outras drogas ainda são mais comuns entre os homens, entretanto mudanças no papel social da mulher têm determinado a diminuição dessa diferença. $O$ envolvimento feminino com as drogas é a principal causa da prisão de mulheres no Brasil'.

Segundo os dados do Levantamento Nacional de Informações Penitenciárias- INFOPEN MULHERES, 2014, ○ Brasil conta com uma população de 579.7811 pessoas custodiadas no Sistema Penitenciário, sendo 37.380 mulheres e 542.401 homens. No período de 2000 a 2014, o aumento da população feminina foi de $567,4 \%$, enquanto a média de crescimento masculino, no mesmo período, foi de 220,20\%, refletindo, assim, a curva ascendente do encarceramento em massa de mulheres no Brasil ${ }^{2}$.

Em torno de 58\% dessas mulheres possuem vinculação penal por envolvimento com o tráfico de drogas não relacionado a grandes redes de organizações criminosas. A maioria delas ocupa uma posição coadjuvante nesse tipo de crime, realizando serviços de transporte de drogas e pequeno comércio; muitas são usuárias, sendo poucas as que exercem atividades de gerência do tráfico ${ }^{2}$. Assim, o envolvimento com drogas, seja qual for o tipo, constitui um elemento de vulnerabilidade para as mulheres.

De um modo geral, o enfoque nas pesquisas sobre o envolvimento de mulheres com drogas ilícitas aponta a participação das mesmas como coadjuvantes do processo, advindas de relações de afeto com homens do sev entorno social: companheiro, irmão, namorado e/ou amigos ${ }^{3}$. Além de apontarem também à banalização da violência, a desestruturação familiar, a falta de acesso à educação, aos recursos básicos de sobrevivência, as altas taxas de desemprego, o subemprego, a desestruturação das relações interpessoais e os motivos passionais como fatores que podem induzir à criminalidade feminina ${ }^{4}$. Entretanto o envolvimento também ocorre pelo desejo de obter poder e visibilidade social ${ }^{5-8}$.

As situações nas quais as mulheres aparecem sós, como decorrência de escolhas pessoais, são pouco exploradas, fato este que pode estar associado à imagem da mulher, historicamente construída, que não está de acordo com a imagem/representação social de pessoa usuária de droga e/ou participante do narcotráfico, o que contribui para $\circ$ processo de invisibilidade das mulheres no fenômeno das drogas e, consequentemente, em vulnerabilidade aos agravos sociais e de saúde para este grupo populacional.

A vulnerabilidade é um indicador da iniquidade e da desigualdade social. Seu conceito tem caráter multidisciplinar e inclui a detecção das fragilidades, mas também a capacidade de enfrentamento dos problemas e/ou agravos de saúde de grupos ou indivíduos?.

A vulnerabilidade engloba três dimensões: individual, programática e social. A dimensão individual considera que a vulnerabilidade é determinada por condições cognitivas (acesso à informação, reconhecimento da suscetibilidade e da eficácia das formas de prevenção), comportamentais (desejo e capacidade de modificar comportamentos que definem a suscetibilidade) e sociais (acesso a recursos e capacidade de adotar comportamentos de proteção) ${ }^{10}$ os autores referem que esta dimensão diz respeito à ação individual de prevenção frente a uma situação de risco que envolve aspectos relacionados a características pessoais (idade, sexo, raça, etc), ao desenvolvimento emocional, percepção do risco e atitudes voltadas à adoção de medidas de autoproteção" .

A dimensão programática contempla o acesso aos serviços de saúde, a forma de organização desses serviços, o vínculo que os usuários dos serviços possuem com os profissionais de saúde, as ações preconizadas para a prevenção e o controle do agravo e os recursos sociais existentes na área de abrangência do serviço de saúde ${ }^{10}$.

A dimensão social integra as características do espaço social, as normas sociais vigentes $e$, as relações de gênero, as iniquidades, entre outros aspectos; utilizando-se de indicadores que identifiquem o perfil da população da área de abrangência quanto ao acesso à informação, gastos com serviços sociais e de saúde; inclui o ciclo de vida, a mobilidade social e a identidade social, isto é, esta dimensão refere-se à estrutura econômica, a 
políticas públicas e relações de gênero que definem a vulnerabilidade individual e a programática.

A incorporação do conceito de vulnerabilidade em pesquisas que tratam de problemas e de necessidades de saúde é fundamental, pela complexidade do objeto da saúde, sobretudo quando se trata de pessoas e/ou grupo social, cultural e historicamente submetido a situações de desigualdades, como as mulheres ${ }^{12}$. Ademais, a perspectiva da vulnerabilidade permite articulação com outras teorias, a exemplo da Teoria das Representações Sociais (TRS).

As representações sociais são formas de conhecimento socialmente elaboradas e partilhadas, que privilegiam o conhecimento do senso comum pela sua dinamicidade e articulação com a situação sócio-político-cultural, na qual o sujeito está inserido ao integrar elementos afetivos, mentais e sociais à compreensão do contexto social, material e ideativo em que vivemos. Desse modo, as respostas individuais são reflexos das manifestações do grupo social com o qual o sujeito compartilha experiências e vivências da sua vida pessoal ${ }^{13}$.

Diante das questões abordadas e considerando que o envolvimento com drogas, independente da modalidade, gera e, ao mesmo tempo, se dá em decorrência de elementos de vulnerabilidade para as mulheres, este artigo tem como objetivo descrever elementos de vulnerabilidades no envolvimento feminino com drogas.

\section{MÉTODOS}

A pesquisa teve como campo de investigação o Conjunto Penal Feminino de Salvador, BA, cuja finalidade é custodiar mulheres em situação de prisão presas processadas (presas que estão em processo de julgamento por serem acusadas de algum tipo de infração à lei) e sentenciadas (presas que foram julgadas e condenadas) dando cumprimento às penas privativas de liberdade, em regime fechado e semiaberto.

A escolha desse lócus se deu basicamente pelo interesse em investigar mulheres em situação de privação de liberdade, considerada um grupo socialmente excluído e estigmatizado, portanto, com pouca visibilidade e muitas situações de vulnerabilidade. Esse interesse surgiu diante da inserção de uma das pesquisadoras no local de investigação desenvolvendo atividades como psicóloga, o que facilita o acesso ao público alvo.

Os dados apresentados constituem recorte de uma pesquisa descritiva, exploratória, de abordagem qualitativa, cujos dados foram coletados com mulheres custodiadas no Conjunto Penal Feminino de Salvador, BA no período de outubro a novembro de 2015. O projeto foi aprovado pelo Comitê de Ética de Medicina da UFBA, parecer 1249920 , e os critérios éticos previstos na Resolução 466/12 foram respeitados em todas as etapas da pesquisa ${ }^{14}$.

Para a identificação das mulheres recorreu-se aos arquivos da Coordenação de Registro e Controle (CRC) da instituição, o qual quantifica o número de mulheres aprisionadas pelos diferentes atos infracionais. No início da coleta de dados, em outubro de 2015 a unidade contava com 138 mulheres custodiadas, dessas 48 sentenciadas sendo 32 por delitos relacionados ao envolvimento com drogas $^{15}$.

A seleção das participantes se deu diante dos seguintes critérios: estar sentenciada (presa que foi julgada e condenada) pelo artigo 33 (tráfico de drogas) e/ou pelo artigo 35 (associação ao tráfico de drogas) ou quaisquer outras infrações relacionadas ao fenômeno das drogas que se apresentavam aparentemente lúcida e consciente para responder os instrumentos de produção dos dados, independente do grau de escolaridade. Nesse contexto, foram investigadas onze mulheres.

A pretensão era envolver todas as mulheres que atendiam aos critérios de inclusão, sobretudo, pela complexidade da temática e escassez de estudos sobre o protagonismo feminino no fenômeno das drogas. Contudo, situações inerentes ao contexto penitenciário, a exemplo de suspensões de atendimentos e entrevistas devido a questões de segurança e a inúmeros eventos realizados na unidade prisional no período da coleta de dados, bem como o tempo limitado da pesquisa por determinações acadêmicas reduziram o número de 
participantes na pesquisa.

Para captação das informações foram aplicadas duas técnicas adequadas à pesquisa qualitativa: a entrevista semiestruturada e o desenho estória com tema. A entrevista ${ }^{8}$ semiestruturada foi guiada por um roteiro com três questões inerentes ao objetivo: 1 - Fale-me sobre o que você pensa sobre as mulheres e as drogas; 2 - Em sua opinião, por que as mulheres se envolvem com as drogas; 3- Para você o que pode ser feito para reduzir os riscos para as mulheres, no envolvimento com as drogas?

O desenho-estória com tema foi aplicado individualmente, sendo utilizada folha de papel em branco sem pauta, lápis preto e caixa de lápis de $\operatorname{cor}^{16}$. Diante da disponibilidade desse material, foi solicitado às participantes fazer um desenho norteado pelo seguinte tema: "as mulheres e as drogas", com base no desenho contar uma estória e finalmente colocar um título. $O$ desenho e as estórias foram lidos e discutidos com as participantes buscando entendimento dos elementos apresentados.

Esta técnica projetiva constitui-se na reunião de processos expressivos-motores (o desenho), processos aperceptivos-dinâmicos (verbalizações temáticas) e associações dirigidas do tipo inquérito mediante o qual é possível ter acesso às ideias e às emoções do sujeito de forma mais espontânea ${ }^{17}$. A escolha da técnica se deu pela possibilidade que a mesma apresenta de aproximação com as participantes da pesquisa pela livre expressão de crenças e valores com relação à problemática do fenômeno das drogas, as quais poderiam ser reprimidas somente com a aplicação da entrevista semiestruturada.

A aplicação das técnicas ocorreu na instituição em salas de atendimento da equipe de saúde, com a presença apenas da pesquisadora. Os dados foram coletados em um encontro individual com duração média de uma hora e trinta minutos.

De um modo geral, as participantes inicialmente reagiram à aplicação da técnica projetiva informando que não sabiam desenhar. Contudo, ao receber explicação de que o objetivo não era avaliar a capacidade de desenhar e nem as habilidades artísticas e que o desenho poderia ser feito da forma que elas quisessem e sabiam fazer respeitando a temática proposta apenas, elas ficaram mais tranquilas e realizaram o que foi solicitado, sem maiores dificuldades.

Os dados foram analisados de acordo com a análise de conteúdo temática. Existem três diferentes fases na análise de conteúdo: a pré-análise; a exploração do material; e o tratamento dos resultados, inferência e interpretação. Dentro destas fases foi realizada a categorização que segundo a autora trata-se de uma operação de classificação de elementos construtivos de um conjunto, por diferenciação e, seguidamente, por reagrupamento segundo $\circ$ gênero (analogia), com os critérios previamente definidos (p. 147). As categorias são rubricas ou classes, as quais reúnem um grupo de elementos sob um título genérico, agrupamento este feito em função das características comuns destes elementos ${ }^{18}$.

Foi adotada neste estudo a categorização temática semântica (categorias temáticas) por permitir analisar a descrição do conteúdo que emergiu das técnicas utilizadas. Assim, a análise dos dados ocorreu da seguinte forma: inicialmente organizouse $\circ$ material coletado por meio da entrevista e desenho estórias, transcrevendo-as na íntegra; em seguida realizou-se uma leitura flutuante das informações coletadas. Após essa primeira leitura, foram realizadas leituras de forma mais aprofundada do material coletado, com vista a registrar impressões sobre as mensagens emitidas. Posteriormente foram elaboradas categorias deste estudo no intuito de se estabelecer classificações.

\section{ASPECTOS ÉTICOS E ACADEMICOS NA PESQUISA}

A presente pesquisa cumpriu todas as salvaguardas éticas e normas regulamentadoras de pesquisas envolvendo seres humanos, estabelecidas pela Resolução CNS 466/12 do Conselho Nacional de Saúde.

A Resolução 466/12 incorpora, sob a ótica do indivíduo e das coletividades, referenciais da 
bioética, tais como, autonomia, não maleficência, beneficência, justiça e equidade, dentre outros, e visa a assegurar os direitos e deveres que dizem respeito aos participantes da pesquisa, à comunidade científica e ao Estado ${ }^{14}$.

Em cumprimento ao princípio da autonomia as informantes receberam orientações acerca da participação voluntária e da possibilidade de desistência em qualquer fase da pesquisa sem nenhum prejuízo, inclusive na sua pena. Quanto ao princípio da justiça, foi garantido o anonimato, $\circ$ sigilo e o respeito à individualidade. Em relação ao princípio da beneficência foi acordado com representantes legais da instituição a apresentação dos resultados da pesquisa após defesa da dissertação no espaço acadêmico.

O tema e método de pesquisa embora não abordasse questões individuais, poderia causar algum constrangimento às internas ao relatar suas opiniões e crenças sobre a temática das drogas, e/ ou sentir sua privacidade invadida com a presença e perguntas da pesquisadora. Visando reduzir os mesmos, os depoimentos foram coletados em uma sala reservada, sem interrupções de pessoas estranhas de modo a preservar o sigilo das informações e a privacidade das depoentes atendendo assim - princípio da não maleficência. Se mesmo assim, houvesse qualquer tipo de constrangimento lhe seria oferecida assistência psicológica, no espaço da instituição, visando amenizar qualquer mal-estar psíquico, casos estes que não foram precisos.

Todas as informações acerca dos princípios básicos foram descritas no Termo de Consentimento Livre e Esclarecido (TCLE), oferecidos as participantes para leitura e assinatura prévia a aplicação das técnicas de aproximação e produção dos dados.

Faz-se importante ressaltar que 0 fato da pesquisadora pertencer ao quadro de funcionários da instituição em que se desenvolveu a pesquisa, na função de psicóloga, apresentou vantagens e desvantagens. Vantagem de ter acesso fácil e diário ao seu objeto de estudo e total aceitação das entrevistadas em aceitar a participar da pesquisa. Porém ao mesmo tempo, motivou obstáculos a vencer, sendo necessário expor com clareza para as internas que meu papel enquanto pesquisadora era diferente do papel de psicóloga que desenvolvo na instituição, visando não levar confusões nos respectivos papeis, iniciando a coleta de dados colocando claramente os objetivos da pesquisa, e a ênfase do fato que os dados expostos não prejudicariam em sua situação na justiça, ou mesmo nas relações com a administração da instituição, já que seria garantido o absoluto sigilo de suas identidades.

Foi salientado também que a pesquisa não fazia parte do trabalho de avaliação para concessão de benefício legal desenvolvido pela psicóloga e, portanto, não tinha vínculo com o judiciário. Esse cuidado visou afastar a dissimulação e a tentativa de responderem de acordo com o que suponham ideal para alcançar o benefício.

Deve ser reconhecido, porém, que os conflitos de interesses são inevitáveis na vida acadêmica. O desafio é reconhecê-los e manejá-los adequadamente, para tal, o projeto foi submetido e aprovado pelo Comitê de Ética de Medicina da UFBA, parecer 1249920, e os 11 critérios éticos previstos na Resolução 466/12 foram respeitados em todas as etapas da pesquisa.

\section{RESULTADOS E DISCUSSÃO}

Considerando a complexidade da temática e os princípios da TRS, antes da descrição propriamente dita dos resultados, será apresentada a caracterização das participantes visando contextualizar as informações para compreensão dos resultados para o grupo investigado. Em seguida serão apresentadas as categorias empíricas identificadas no processo de análise dos dados, as quais evidenciam elementos de vulnerabilidade para o envolvimento feminino com as drogas.

\section{CARACTERIZAÇÃO DAS PARTICIPANTES DO ESTUDO}

As 11 mulheres investigadas tinham idade entre 22 
e 55 anos, sendo predominante a faixa etária de 32 a 37 anos. Quanto ao quesito raça/cor oito mulheres se consideram pardas e três negras. Em relação à escolaridade e ocupação, constatou-se um nível de instrução baixo, onde a maioria das mulheres possui o ensino fundamental incompleto e quanto à situação de emprego predomina o trabalho no mercado informal como domésticas, auxiliares de serviços gerais, autônoma e manicure, seguido pelo desemprego e trabalho formal. A renda mensal das participantes variou de $\mathrm{R} \$ 260,00$ a $\mathrm{R} \$ 30.000,00$ reais, sendo que a maior parte destas recebia menos de um salário mínimo.

Em relação ao estado civil oito das participantes declararam estar solteiras, destas, três tinham companheiro antes de serem presas, e as demais viviam em regime de união estável, predominando mulheres na condição de chefes de família, ou seja, as principais provedoras do sustento financeiro. Dez participantes tinham filhos, sete delas com idade que variava entre 3 a 17 anos, e o restante possuíam filhos acima de 18 anos. Todas as participantes do estudo eram brasileiras, sendo oito procedentes do interior da Bahia e região metropolitana de Salvador, duas de Salvador e uma era de São Paulo.

Com relação à situação na criminalidade, sete das entrevistadas eram rés primária e quatro reincidentes. É considerada primária a presidiária que cometeu apenas um delito e está presa em decorrência deste, enquanto que a reincidente já foi presa anteriormente por ter cometido novo crime ${ }^{19}$. Quanto ao período de ingresso na instituição, o tempo de custodiadas variavam de 4 meses a 2 anos e 5 meses. Todas as mulheres estavam sentenciadas em regime fechado. No regime fechado, a mulher cumpre a pena em estabelecimento de segurança máxima ou média (penitenciária), ficando sujeita a isolamento no período noturno e trabalho no período diurno, este trabalho será dentro do estabelecimento, de acordo com as suas aptidões, desde que compatíveis com a execução de pena, admitindo-se o trabalho externo apenas em serviços ou obras públicas. O tempo de cumprimento/ condenação das penas das entrevistadas variou de 4 anos e 8 meses a 18 anos de prisão.

Em se tratando dos dados de saúde, do total de participantes, seis declararam não possuir nenhuma doença e as demais informaram ter: hérnia, mioma, estrabismo, hipertensão asma, e gengivite. Estas alterações não foram relacionadas ao consumo de substâncias psicoativas. Quanto ao uso de drogas, duas revelaram consumir álcool e tabaco e oito usavam maconha, cocaína, crack e extasy, a outra negou uso de qualquer dessas substâncias.

\section{VITIMIZAÇÃO, PROTOGONISMO E SOFRIMENTO NUM CONTEXTO DE NECESSIDADES E DESIGUALDADES}

De um modo geral, os relatos e estórias das participantes evidenciam que seu envolvimento com as drogas se deu por conta da convivência com homens usuários de drogas e/ou participantes do narcotráfico, na condição de companheiro e/ou amigo; dificuldades financeiras; condição de chefe de família; traumas/revoltas oriundas das relações familiares e do cotidiano, reafirmando um discurso de vitimização. Embora de maneira discreta, reconhecem que o consumo e a participação no narcotráfico ocorrem por uma decisão pessoal, na busca de visibilidade. $E$, afirmam que $O$ envolvimento com drogas causa sofrimento, não apenas para si, mas também para os familiares.

No tocante aos elementos de vulnerabilidade para o envolvimento com as drogas, as entrevistadas destacaram a influência de pessoas do sexo oposto na condição de parceiro e/ou amigos, conforme mostra trechos dos discursos e o desenho estória a seguir:

Meu marido insistia em vender drogas. $E$ eu querendo fazer as coisas para agradar aceitava. (EO 1, 34 anos, 4 filhos, reincidente)

As mulheres se envolvem também por causa da maioria dos homens que elas pegam... Eu mesmo me envolvi com as drogas para pagar um advogado para um ex-companheiro meu, para tirar ele da cadeia passei a vender drogas... (E02, 55 anos, 4 filhos, reincidente)

As mulheres por causa dos homens muitas vezes se envolvem no tráfico, mesmo que não venda, só por estar junto a polícia diz que está envolvida... No meu caso me envolvi com droga por causa de amizade, fui 
apoiar traficante, dar dormida, guardar as drogas dele, as armas. Já as mulheres em geral por causa do companheiro que elas se envolvem... (E07, 33 anos, 1 filho, primária)

Muitas vezes um amigo também bota pressão. Muitas vezes, o marido as obriga a levar drogas no presídio ou a vender também. Muitas fazem obrigadas por ameaças. (EO 10, 22 anos, 0 filho, primária)

\section{OBRIGADAS A TRAFICAREM, SEREM MULAS DO CRIME!} (E010, 22 anos, 0 filhos, primária)

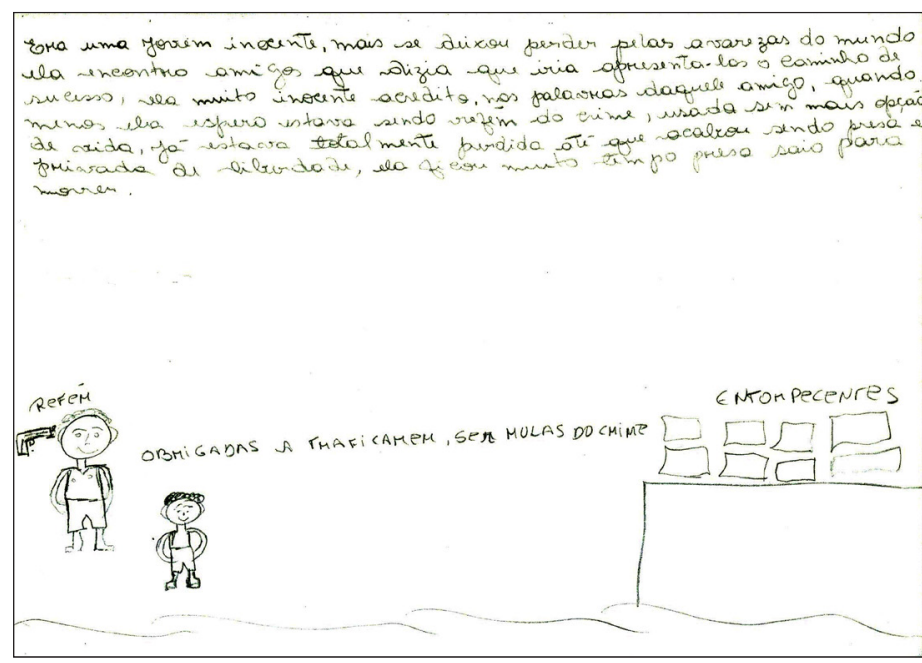

ESTÓRIA: Era uma jovem inocente, mais se deixou perder pelas avarezas do mundo, ela encontrou amigos que dizia que iria apresenta-los o caminho de sucesso, ela muito inocente acreditou nas palavras daquele amigo, quando menos ela esperava estava sendo refém do crime, usada sem mais opção de vida, já estava totalmente perdida até que acabou sendo presa e privada de liberdade, ela ficou muito tempo presa e saiu para morrer ${ }^{14}$.

De acordo com as entrevistadas, muitas mulheres sob influência de terceiros e almejando ter melhores condições entram na criminalidade e após inserirse nesta não tem mais opções: viram vítimas, reféns do crime, como consequência the resta a vida em cárcere e a morte. Desta forma, a participação feminina no tráfico de drogas, em vez de motivada por uma escolha pessoal, é descrita como o resultado da influência de terceiros envolvidos na atividade. Nesse contexto, reafirmam a ideia de subordinação das mulheres aos homens e confirmam o discurso de vitimização das mulheres para $\circ$ envolvimento com drogas e criminalidade ${ }^{6,7}$.

Apoiadas na ideia de vitimização, as entrevistadas sinalizam as dificuldades econômicas associadas à falta de emprego e oportunidades de trabalho como elementos relevantes para seu envolvimento com as drogas, conforme relatos e desenho estória a seguir:

As mulheres às vezes se envolvem com as drogas porque não tem trabalho no Brasil, está muito difícil trabalho no país todo. Ai se envolve para poder ajudar a sua familia, principalmente quem tem filhos. Deveria ter mais trabalho... (EO6, 42 anos, 2 filhos, primária)

Às vezes se envolvem, vendem as drogas porque precisa. É preciso dar mais oportunidades de trabalho para mudarmos a nossa vida, se sairmos com emprego não precisaremos mais voltar. (E1 1, 35 anos, 5 filhos, reincidente)

As mulheres entram no mundo das drogas por ter dificuldades. Acho que às vezes por necessidade, por ver um filho pedindo pão e não tem, para manter a casa, porque muitas vezes o marido é encostado, não faz nada e essa mulher por gostar dele se sacrifica, sacrifica a sua vida, correndo perigo. Que a sociedade olhasse mais para essas mulheres, que elas estão precisando de oportunidades e não estão achando e por isso não saem do tráfico... Muitas não conseguem um emprego por não ter experiência, ai o tráfico abre as portas e aceita estas mulheres, tem que ter mais oportunidades. (E09, 33 anos, 2 filhos, primária)

\section{A NECESSIDADE LEVOU A ISSO, A VENDER DROGAS! (E09, 33 anos, 2 filhos, primária)}

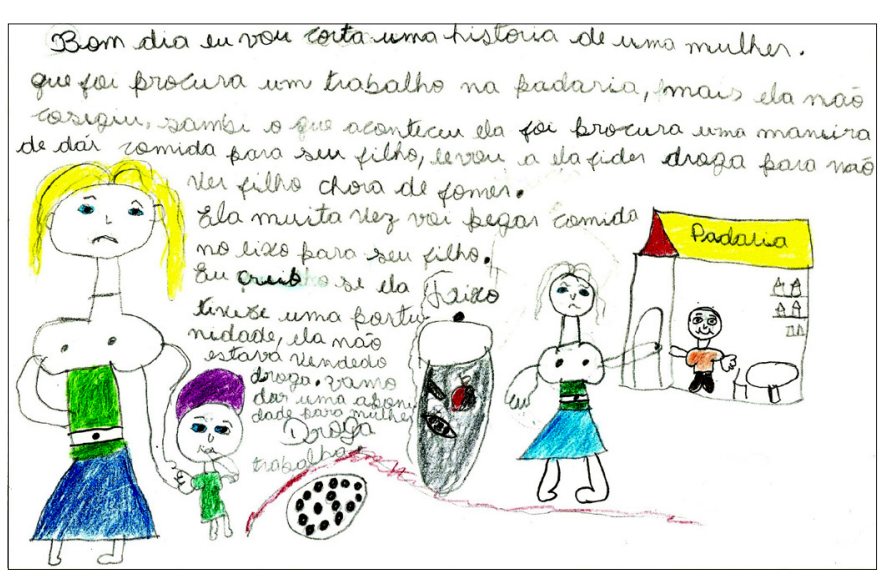

ESTÓRIA: Bom dia, eu vou contar uma história de uma mulher que foi procurar um trabalho na padaria, 
mas ela não conseguiv, sabe o que aconteceu, ela foi procurar uma maneira de dar comida para seu filho, levou ela a vender droga para não ver seu filho morrer de fome. Ela muitas vezes foi pegar comida no lixo para seu filho. Eu creio que se ela tivesse uma oportunidade, ela não estava vendendo droga, vamos dar uma oportunidade para essa mulher, trabalho.

Para as entrevistadas, o tráfico de drogas é uma alternativa no contexto em que vivem, onde a maioria está na condição de chefe de famílias e ingressam nesta atividade por falta de opções, cujo comércio ilegal de drogas representa muitas vezes a única forma de sustento para elas e para as famílias ${ }^{20,21}$.

Ressaltaram ainda que a discriminação, o estigma de ex-presidiária e a falta de esperança são elementos marcantes para manutenção do envolvimento com o tráfico de drogas. No discurso das entrevistadas, 0 tráfico mostra-se como a única opção de trabalho e renda no contexto de desigualdades que marcam as suas vidas:

\section{MULHERES LUTEM MAIS PELOS SEUS DIREITOS!} (E04, 24 anos, 1 filho, primária)

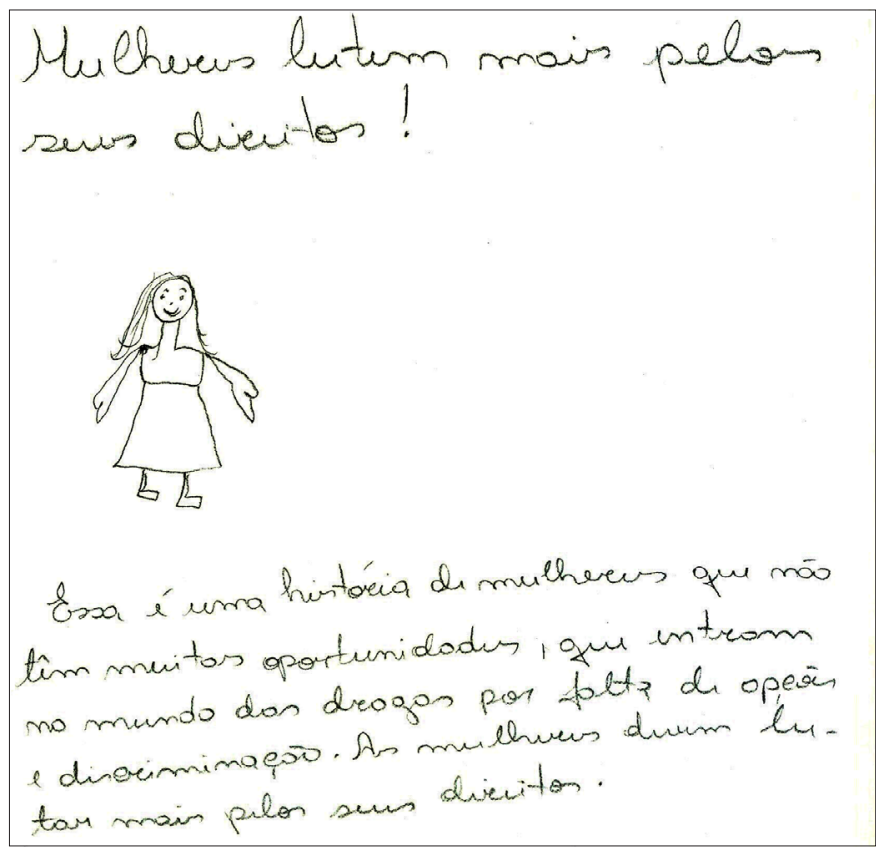

ESTÓRIA: Essa é uma história de mulheres que não tem muitas oportunidades, que entram no mundo das drogas por falta de opções e discriminação. As mulheres devem lutar mais pelos seus direitos ${ }^{16}$.

Às vezes as mulheres vão para o mundo das drogas por falta de opção e discriminação. Não temos muitas oportunidades, são mais para os homens, como por exemplo, o emprego. Deveria ter mais oportunidades de emprego. Menos uma sociedade machista que da mais oportunidade aos homens. (E04, 24 anos, 1 filho, primária)

Quando a pessoa vem presa pela primeira vez, sai e não acha oportunidades de trabalho, ninguém quer dar oportunidades a um ex-presidiário, ai a pessoa volta a vender drogas, a se prostituir, roubar. Deveria ter oportunidades de trabalho, porque ai não vai ter como se envolver com drogas, ninguém quer dar um trabalho para a pessoa, seja qualquer trabalho. (E08, 32 anos, 4 filhos, reincidente).

O posicionamento das participantes evidencia desigualdades de gênero, sociais e econômicas que permeiam as relações cotidianas do contexto no qual estão inseridas e demarcam elementos de vulnerabilidade para as mulheres. Nesse sentido, ressaltam que $\circ$ estigma conferido a mulher expresidiaria contribui ainda mais para limitação de oportunidades de emprego formal e legal. E, nessse contexto, o tráfico de drogas se mostra como uma modalidade de trabalho, sem vínculos formais, mas com a possibilidade de ganhos para suprir demandas da sobrevivência, embora com riscos de perda da liberdade e de morte.

No discurso das entrevistadas traumas por situações vivenciadas na infância ou adolescência e falta de afeto familiar foram elementos que contribuíram para o início do consumo de drogas, conforme relatos a seguir:

As mulheres se envolvem com as drogas por causa do marido que bate, e por algo que aconteceu quando eram criança ai muitas mulheres se revoltam. (E05, 26 anos, 1 filho, primária)

Muitas se envolvem nesse mundo porque não tem atenção, carinho de pai e mãe (E08, 32 anos, 4 filhos, reincidente)

As mulheres, a maioria se envolve por depressão, sentir um vazio, acha que vai encontrar um refúgio nas drogas. Às vezes traição, decepção, leva as mulheres a usar drogas. (E010, 22 anos, 0 filhos, primária)

Com base no conceito de vulnerabilidade e no discurso das entrevistadas, pode-se afirmar que - consumo de drogas se constitui uma estratégia 
de enfrentamento para situações de violência doméstica, traumas e revoltas ocorridas na vida delas. Contudo, essa estratégia torna-se um elemento de vulnerabilidade para manutenção do uso, além dos riscos decorrentes da ilegalidade.

Contradizendo o discurso de vitimização, as entrevistadas apontaram, mesmo que de forma discreta, o desejo de adquirir bens e independência financeira, assim como ter poder e reconhecimento social como elementos para seu envolvimento com drogas.

Muitas mulheres fazem porque gostam, porque acham que é a mulher maravilha. Para ser reconhecida como patroa, para ser mais do que todo mundo, para se achar a dona do pedaço, para ser vista na sociedade. Eu mesma entrei na criminalidade por causa do poder, pois tinha uma vida estruturada e apoio familiar. (E 10, 22 anos, 0 filhos, primária)

... No meu caso eu comecei a vender drogas porque eu quis ninguém me influenciou, o meu companheiro mesmo sempre trabalhou honestamente, mas eu resolvi sozinha vender drogas. (E08, 32 anos, 4 filhos, reincidente).

As mulheres se envolvem para atingir a independência. A mulher fica mais dentro de casa lavando, passando, cozinhando. O homem trabalha, traz dinheiro para casa e joga na cara da mulher isso. (EO4, 24 anos, 1 filho, primária)

As mulheres se envolvem com as drogas para ostentar, porque acha dinheiro fácil (EO1, 34 anos, 4 filhos, reincidente)

Os trechos revelam a responsabilização pela escolha, assumindo que o envolvimento com as drogas se deu também pela busca de poder e respeito, conferidos àquelas que conseguem atingir a condição de traficante e de chefes da boca de fumo. Assumem de forma discreta e, às vezes, conflituosa o papel de protagonistas das suas histórias.

O protagonismo feminino no fenômeno das drogas é discutido através da análise de reportagens publicadas em revistas de circulação nacional. As referidas autoras destacaram aspectos que evidenciam a participação de mulheres no consumo e tráfico de drogas ilícitas, sem relação direta com a influência de companheiros e/ou amigos, protagonismo este que segundo o estudo ainda são poucos explorados, mas que começam a ser considerados ao verificarem reportagens que trazem uma iniciativa própria feminina como motivadores para o envolvimento com drogas ${ }^{3}$.

O protagonismo das mulheres no envolvimento com drogas é ressaltado, assinalando a inserção de mulheres no tráfico de drogas como estratégia de saída da invisibilidade social feminina, que se dá principalmente pela diferenciação destas mulheres, pela afirmação de um poder antes exclusivo dos homens e pelo reconhecimento externo deste poder.

Os relatos confirmam o que Pereira (2008) assinala no estudo com mulheres presas de uma penitenciária feminina de Belo Horizonte no qual se verificou que a entrada da mulher no tráfico de drogas representou mais que um busca de status econômico, ao constatar que a atividade ilícita fora motivada também pela busca da autonomia e da possibilidade real de conquistar visibilidade social e poder pela via criminosa $^{22}$.

Para as participantes, o envolvimento com drogas causa sofrimento, não apenas para si, mas também para a família. Os relatos e desenhos retratam sofrimentos pela perda da guarda dos filhos ou pelo afastamento dos mesmos diante da sua condição de usuária e/ou traficante. $E$, nessa perspectiva repetem frases/ideias socialmente compartilhadas quanto à importância da família e condenação para o uso de drogas, como se constata com as seguintes produções:

A droga é péssima, leva a pessoa para o calabouço. Acho que deveria pensar mais na família para não se envolver. A familia sofre mais do que a gente. (EO7, 33 anos, 1 filho, primária)

Eu penso que as drogas vieram para destruir fisicamente, como em outras áreas, a exemplo do relacionamento na família, no meio, na sociedade. (E010, 22 anos, 0 filhos, primária) 
SOFRIMENTO!

(E01, 34 anos, 4 filhos, reincidente)

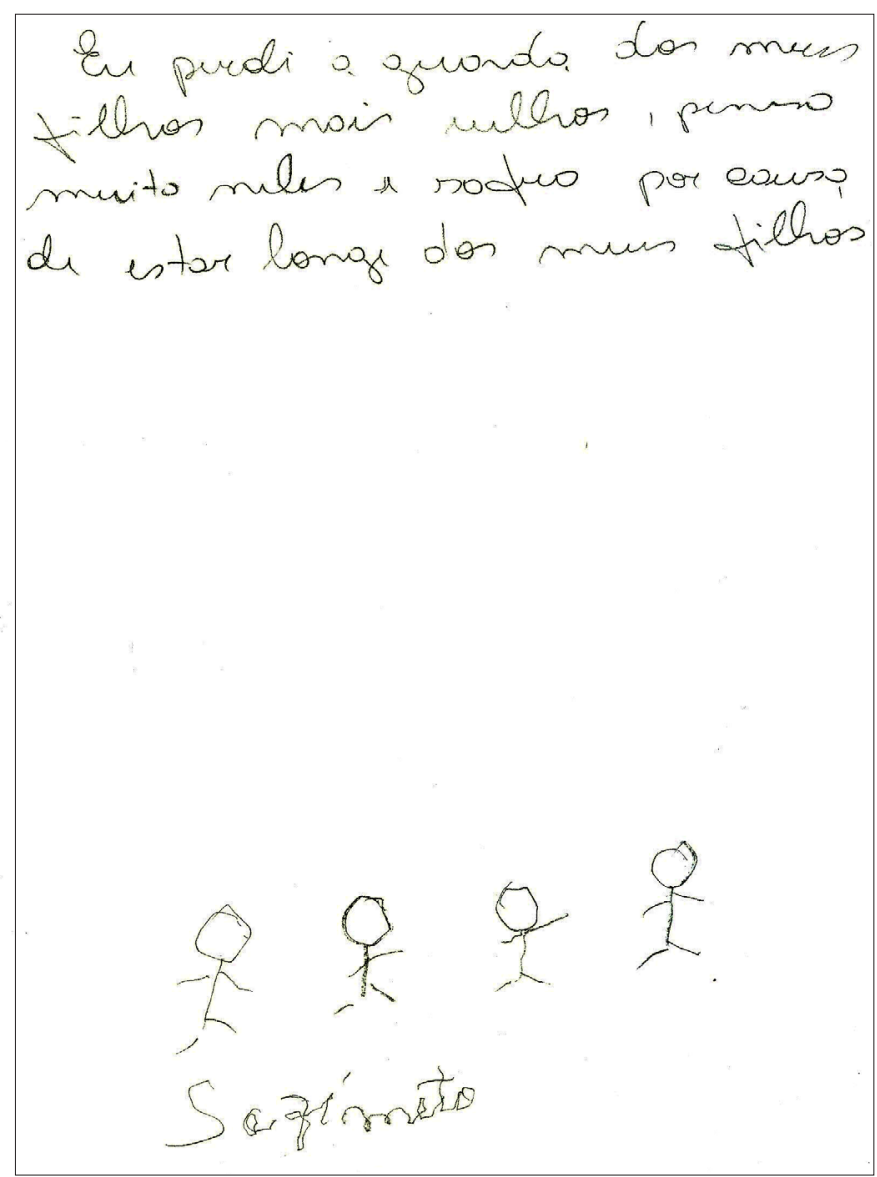

ESTÓRIA: Eu perdi a guarda dos meus filhos mais velhos. Penso muito neles e sofria por causa de estar longe dos meus filhos.

\section{NÃO ÀS DROGAS}

(E02, 55 anos, 4 filhos, reincidente)

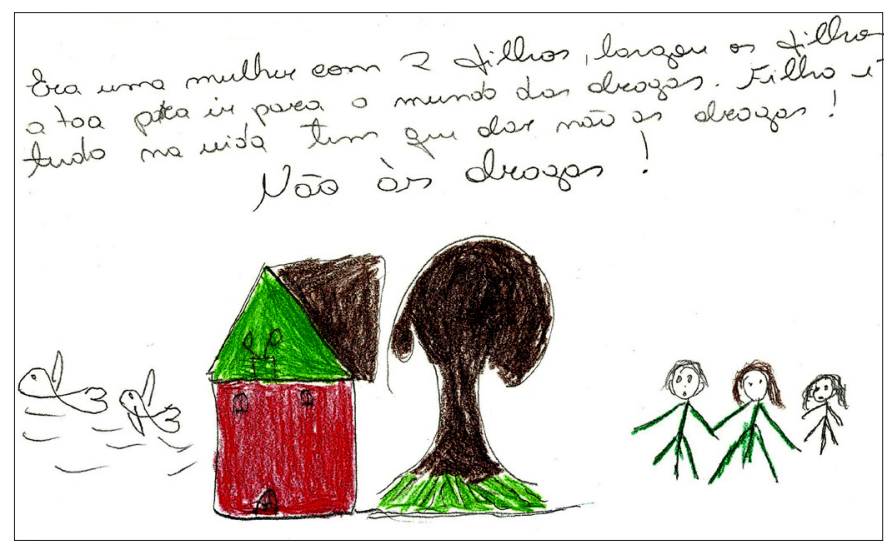

ESTÓRIA: Era uma mulher com dois filhos, largou os dois filhos a toa, para ir para o mundo das drogas. Filho é tudo na vida, tem que dar não às drogas.
MINHA FAMÍLIA, BENÇÃO DO SENHOR! (E07, 33 anos, 1 filho, primária)

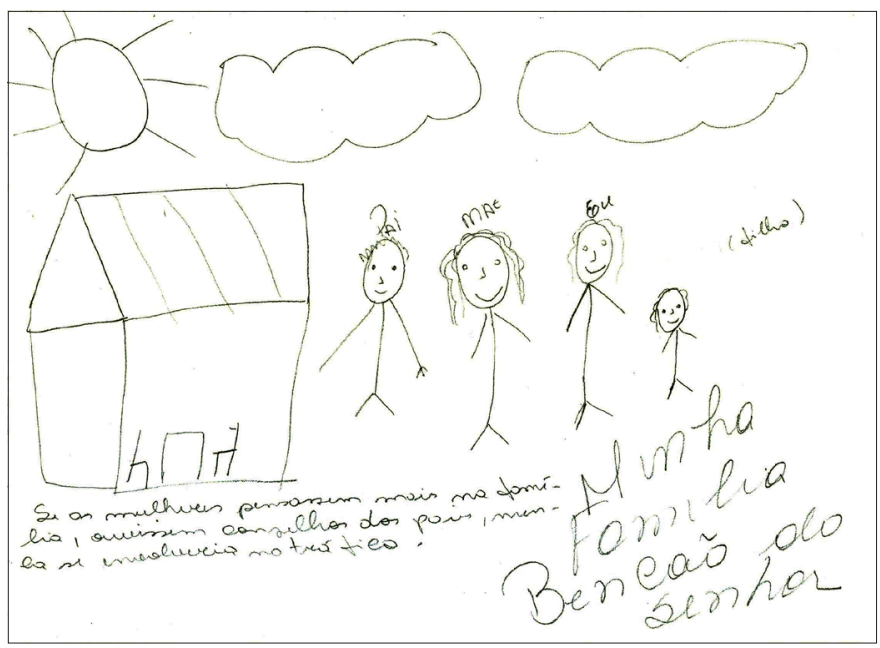

ESTÓRIA: Se as mulheres pensassem mais nas famílias, ouvissem os conselhos dos pais, nunca se envolveriam no tráfico.

No primeiro desenho estória, a participante revela o sofrimento pelo afastamento dos filhos determinado pela justiça, ocorrido em prisão anterior a esta. No segundo e terceiro desenhos-estórias, o afastamento ocorreu devido ao atual aprisionamento. Nestes, a imagem da casa evidencia o desejo das participantes superar esse sofrimento pela esperança de ter uma vida tranquila e retomar ao convívio da família.

Outro elemento que determina sofrimento e vulnerabilidade à manutenção do envolvimento com as drogas diz respeito ao estigma, discriminação e as situaçães de violência vivenciadas pela adoção de condutas socialmente repudiadas, dentre elas o aprisionamento.

\section{MAIS AMOR!}

(E03, 37 anos, 3 filhos, primária)

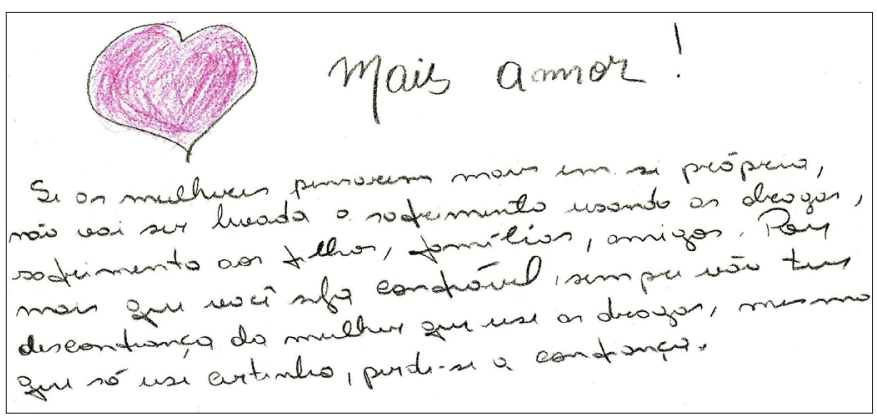

ESTÓRIA: Se as mulheres pensarem mais em si própria, não vai ser levada ao sofrimento usando as drogas. Sofrimento aos filhos, famílias, amigos. Por mais que você seja confiável, sempre vão ter desconfiança da 
mulher que use drogas, mesmo que só use certinho, perde-se a confiança.

O desenho do coração, que segundo a interna simboliza a necessidade de se ter mais amor, referese aqui ao amor próprio que a mulher tem que sentir por si mesma, pois se ela se amar em primeiro lugar não causará sofrimento nem a elas mesmas e nem as suas famílias e demais relações sociais. Finaliza a história apontando a questão do estigma conferido à mulher usuária de drogas, ressaltando que este existe discriminação e desconfiança mesmo quando o uso da droga não é abusivo e nem prejudicial.

Os dados mostram que mulheres envolvidas com drogas estão vulneráveis a sofrimentos causados não só a si mesmas, mas também a toda a sua família, ocasionando, principalmente o afastamento dos filhos, o estigma de ser mulher, usuária de drogas e traficante e as consequências de ingressar na criminalidade. Resultados estes congruentes com pesquisas anteriores realizadas com mulheres aprisionadas ${ }^{23-25}$.

Nos dados analisados foram identificados elementos de vulnerabilidade nas dimensões individual, social e programática, os quais estão interligados e influenciam no envolvimento feminino com as drogas. Os elementos apresentados refletem a condição das participantes $^{21}$ num contexto de desigualdades e na busca de visibilidade. Para as mesmas, o consumo de drogas e a participação no narcotráfico se apresentam como estratégias de enfrentamento, as quais ocasionam dentre outros aspectos, situações de sofrimento para as próprias mulheres e seus familiares, sobretudo afastamento da família.

Nesse sentido, fica evidente, também, a necessidade de ações pautadas em estratégias de saúde, cidadania e direitos humanos voltados para população feminina na tentativa de minimizar possíveis riscos e danos de natureza biológica, psicossocial e econômica, provocados ou secundários ao envolvimento com drogas, como prevê a Lei $n^{\circ}$ 11.343/2006. Esta lei institui o Sistema Nacional de Políticas Públicas sobre Drogas - Sisnad e os princípios de Redução de Riscos e Danos que regem as linhas de cuidados apontados pela mesma ${ }^{15}$.

\section{CONSIDERAÇÕES FINAIS}

Os resultados da pesquisa, embora limitada pelo número de participantes, reafirmaram a complexidade da problemática das drogas, sobretudo quando envolve a população feminina. Para o grupo investigado a influência de companheiro e amigos, traumas/revoltas da vida, violência, sofrimento, dificuldades financeiras e a busca de visibilidade e de poder foram evidenciados como elementos de vulnerabilidade para o envolvimento feminino com as drogas.

Faz-se importante ressaltar que a descrição sociodemográfica das entrevistadas cujo perfil é de mulheres pardas e negras, com baixa escolaridade, renda e qualificação profissional, trabalhando no mercado informal, solteiras e na condição de chefes de família permitem reconhecer que essas mulheres estão inseridas em um contexto socioeconômico cujo envolvimento com a droga e ingresso no sistema prisional pode ser vistos como fatores de vulnerabilidade social.

O conjunto de elementos de vulnerabilidade identificados mostraram basicamente dois posicionamentos: o primeiro e mais predominante nos resultados da pesquisa traz as mulheres como vítimas de um sistema social marcado por desigualdades de gênero permeado por ações de violência, dificuldades financeiras e convivência com pessoas do sexo oposto, usuário e/ou participante do narcotráfico, Neste contexto, o consumo e/ou o tráfico de drogas se mostra como uma estratégia de enfrentamento que gera outras situações de vulnerabilidade. No segundo posicionamento, as mulheres colocam-se como agentes conscientes e responsáveis pelas suas escolhas ao assumir que o ingresso no tráfico de drogas se deu pela busca de poder, status e reconhecimento, enfim para atingir visibilidade social.

Posicionamento de mulheres como agentes em suas decisões favorece uma tentativa de rever teorias deterministas acerca da criminalidade feminina, que justificam que os crimes femininos ocorrem devido ao envolvimento de mulheres com homens criminosos ou pela necessidade destas sustentar suas famílias. Contudo a pobreza e a percebida falta de perspectivas não conduzem necessariamente as 
mulheres ao crime, não podendo ser feita assim uma associação causal entre pobreza e criminalidade. A posição como protagonistas das suas histórias permite entender e dar visibilidade aos diversos contextos em que mulheres figuram como autoras de atividades ilícitas.

Diante dos elementos trazidos, podemos constatar como os discursos de vitimização e de protagonismo foram apropriados pelas participantes em relação ao envolvimento com as drogas. As consequências desse envolvimento seja como vítimas sejam como protagonistas resultaram no sofrimento causado não só a mulher como a sua família. Sofrimento este que acarretaram o encarceramento e junto a ele 0 afastamento da família, principalmente dos filhos, relações sociais, o estigma de ser mulher, usuária de drogas e traficante.

Os resultados desta análise evidenciam a necessidade de investimento em políticas públicas prioritariamente articuladas entre educação, qualificação profissional e emprego, a fim de reduzir a violência estrutural que sofrem estas mulheres, bem como a criação de programas, ações de saúde que ampliem a oferta de serviços de saúde na atenção ao uso de drogas.

Pode-se, portanto, através de tal pesquisa se abrir um caminho para uma reflexão crítica sobre os elementos de vulnerabilidade no envolvimento de mulheres com drogas e contribuir para implantação de projetos de intervenção com as mulheres privadas de liberdade, para que possa se trabalhar o tema das drogas a partir de estratégias de redução de riscos e danos, dadas a condição geral de vulnerabilidade derivada da situação em que se encontra a população carcerária de modo a contribuir para o planejamento e implantação de ações que atendam as especificidades do grupo estudado, a integralidade da saúde e a redução de riscos e danos.

Portanto, a realização da mesma indubitavelmente contribuirá para fortalecer os estudos acerca das questões de gênero, mulher, saúde e drogas tendo em vista a melhoria do cuidado em saúde prestado às mulheres envolvidas com as drogas em privação de liberdade.

\section{REFERÊNCIAS}

1. Brasil. Ministério da Justiça. Departamento Penitenciário Nacional - DEPEN. Brasília. DF. 2011.

2. Brasil. Ministério da Justiça. Levantamento Nacional de Informações Penitenciárias INFOPEN MULHERES. Departamento Penitenciário Nacional DEPEN. Brasília. DF. 2014.

3. Oliveira MRRS, Nascimento JFN, Nascimento ER. A saúde de mulheres e o fenômeno das drogas em revistas brasileiras. Texto Contexto Enfermagem. 2014;23(1):92-100. doi: 10.1590/S010407072014000100011

4. Priori C. Mulheres infratoras e o sistema prisional: uma discussão prévia. [Texto completo]. Anais do IV Congresso Internacional de História. Maringá; 2009; Universidade Federal do Paraná; 2009

5. Barcinski M. Mulheres no tráfico de drogas: a criminalidade como estratégia de saída da invisibilidade social feminina. Contextos Clínicos. 2012;5(1):52-61. doi: 10.4013/ctc.2012.51.06

6. Barcinski M. Protagonismo e vitimização de mulheres envolvidas na rede do tráfico de drogas no Rio de Janeiro. Ciência e Saúde Coletiva. 2016;14(2):577-586. doi: 10.1590/S141381232009000200026

7. Barcinski M. Centralidade de gênero no processo de construção da identidade de mulheres envolvidas na rede do tráfico de drogas. Ciência e Saúde Coletiva. 2009; 14(5):1843-1853. doi: $10.1590 / \mathrm{S} 1413-81232009000500026$

8. Carvalhaes FF, Toneli MJ. Rainhas do tráfico de drogas: imagens de poder. In: Anais do II Simpósio Gênero e Políticas Públicas; 18 e 19 de agosto de 2011 ; Universidade Estadual de Londrina: GT5 Gênero e Violência. 2011.

9. Bertolozzi MR, Nichiata LYI, Takahashi RF, Ciosak SI, Hino P, Val LF et al. Os conceitos de vulnerabilidade e adesão na Saúde Coletiva. Rev. Esc Enferm USP. 2009;43(Esp 2):1326-30. doi: $10.1590 /$ S0080-62342009000600031 
10. Mann J, Tarantola DJM, Netter TW. Aids in the word. Cambridge: Harvard University Press; 1992.

11. Oliveira JF. Vulnerabilidades de mulheres envolvidas com álcool e outras drogas [Projeto de Pesquisa submetido à apreciação do CNPQ Edital $\mathrm{MCTI} / \mathrm{CNPq} / \mathrm{SPM}-\mathrm{PR} / \mathrm{MDA} \mathrm{N}^{\circ} 32 / 2012$ ]. Edital de Gênero - Temática D - Categoria 2; 2012

12. Jodelet $D$. Representações Sociais: Um domínio em expansão. In: JODELET, Denise (Org.). As representações sociais. Rio de Janeiro: EDUERJ; 2001. P. 17-44

13. Brasil. Ministério da Saúde. Conselho Nacional de Saúde. Resolve aprovar diretrizes e normas regulamentadoras de pesquisas envolvendo seres humanos. Brasília. DF. 2012.

14. Brasil. Lei Ordinária $n^{\circ} 11.343$, de 23 de agosto de 2006.

15. Trinca W. Procedimentos de desenhos-estórias: formas derivadas, desenvolvimentos e expansões. 1 ed. São Paulo: Vetor; 2013.

16. Coutinho MPL. Representações sociais e práticas de pesquisa. João Pessoa: UFPB/Editora Universitária; 2005.

17. Bardin L. Análise de conteúdo. Tradução Luis Antero Reto e Augusto Pinheiro. Título original: L'analyse de contenu. São Paulo: Edições 70; 2011. P. 279.

18. Brasil. Código Penal. Decreto-Lei 2.848, de 7 de dezembro de 1940.

19. Moreira VS. Impactos do envolvimento de mulheres presidiárias com o fenômeno das drogas [Dissertação]. Escola de Enfermagem: Universidade Federal da Bahia. Salvador; 2012.

20. Moki, MP. Representações sociais do trabalho carcerário feminino [Dissertação]. Centro de Educação e Ciências Humanas: Universidade de São Carlos; 2005.

21. Pereira SVJ. Trajetórias de vida de mulheres presidiárias envolvidas com o tráfico de drogas em Belo Horizonte [Dissertação]. Belo Horizonte:
Pontifícia Universidade Católica de Minas Gerais; 2008

22. Medeiros LL. Mulheres e Cárcere -Reflexões em torno das redes de Proteção Social. In: X Encontro Nacional de História Oral. Recife. Testemunhos: História e Política; 2010. Recife: Centro de Filosofia e Ciências Humanas, Universidade Federal Fluminense-UFF; 2010.

23. Lopes R. Prisões femininas: um espaço diferente? In: ROVINSKI, S. L. R. ; CRUZ, R. M. (Org). Psicologia Jurídica: perspectivas teóricas e processos de intervenção. 1ed. São Paulo: Vetor; 2009. P 297-309.

24. Almeida, MLO. Vozes de dentro... de mulheres... de muralhas: um estudo sobre jovens presidiárias em Salvador, Bahia [Dissertação]. Faculdade de Filosofia e Ciência Humanas: Universidade Federal da Bahia, Salvador; 2006 [Acesso em: 25.01.2016]. Disponível em: http://www.ppgcs. ufba.br/site/db/trabalhos/1282009130057.pdf 